\title{
Pragmática del insulto: de la prescripción al uso en la agresión verbal entre mujeres ${ }^{1}$ Pragmatics of Insult: from Prescription to Use in Verbal Agression Among Women
}

\section{Cristina Tabernero}

Universidad de Navarra, GRISO

ESPAÑA

ctabernero@unav.es

[Hipogrifo, (issn: 2328-1308), 7.1, 2019, pp. 397-420]

Recibido: 20-04-2018 / Aceptado: 18-05-2018

DOI: http://dx.doi.org/10.13035/H.2019.07.01.31

Resumen. En este artículo se analiza el comportamiento lingüístico de la mujer como agente de violencia verbal, contrastando la prescripción de leyes y tratados con el uso cotidiano. En una primera parte, se revisan las sanciones legales a este respecto como reflejo de una realidad social, y se compara el ideal cortesano con la advertencia de los moralistas sobre la propensión femenina a la comisión de pecados de lengua. En la segunda parte, el análisis de intercambios comunicativos de insultos entre mujeres permite, por un lado, afirmar la quiebra de los tópicos más comunes sobre la lengua femenina y, por otro, caracterizar los usos femeninos frente a los masculinos a partir de los tipos de reacción a la injuria propios de cada sexo.

Palabras clave. Insulto; discurso femenino; siglos XVI y XVII; prescripción; interacción comunicativa.

Abstract. This article analyzes the linguistic behavior of women as an agent of verbal violence through the contrast between the requirement of laws and treaties, on the one hand, and everyday use of language, on the other hand. In a first part, legal sanctions are reviewed as a reflection of a social reality. In addition, the cour-

1. Este trabajo se enmarca en el proyecto Universos discursivos e identidad femenina: élites y cultura popular (1600-1850) (HAR2017-84615-P), del Ministerio de Economía, Industria y Competitividad del Gobierno de España. 
tesy ideal is compared to the warning of moralists about the propensity of females to commit sins of language. In the second part, the analysis of communicative interchanges of insults among women enables to affirm the rupture of the most common topics related to feminine language. Furthermore, this study provides a characterization of feminine uses of language compared to the masculine ones on the basis of the types of response to the linguistic injury specific to each gender.

Keywords. Insult; Feminine discourse; $16^{\text {th }}$ and $17^{\text {th }}$ centuries; Requirement, Communicative interaction.

\section{LA MUJER COMO AGENTE DE LA VIOLENCIA VERBAL EN LA LEGISLACIÓN}

A pesar de lo reiterado de la cita, no estará de más traer de nuevo a un trabajo sobre palabras y expresiones injuriosas la consideración legal de este delito², que, recuérdese, ostenta tal condición por atentar contra la honra, contra la imagen del otro3:

Injuria en latin tanto quiere dezir en romance, como deshonrra ${ }^{4}$, que es fecha, o dicha a otro, a tuerto, o a despreciamiento del; e como quier que muchas maneras son de deshonrra, pero todas descienden de dos raizes. La primera es de palabra. La segunda es de fecho (Partidas, Séptima Partida, título 9, ley 1).

La injuria de acción será, entre las dos posibles, la única reconocida y sancionada en el Liber Iudiciorum (siglo VII), con la particularidad de que incluirá por primera vez a la mujer como elemento activo o pasivo de este delito; más adelante, en el Fuero de Miranda de Ebro (h 1095), se volverá a explicitar la posibilidad de que sea una mujer quien emplee la violencia contra otra persona ${ }^{5}$.

2. Ver el conocido trabajo de Rafael Serra (1969) para la evolución del concepto de injuria y su consideración como delito. Según anota este autor, el delito de injuria se desarrolla como tal en la Edad Media y será en estos siglos cuando adopte una configuración que se conserva esencialmente en la actualidad. 3. En efecto, como señala Serra (1969, p. 62), la evolución de la injuria solo puede entenderse en función de la «variabilidad histórica del honor»: «Imperaba un honor rudo, externo, integral, centrado en valores físicos, tangible, al que corresponde una injuria predominantemente de hecho, manifestada de ordinario en forma de agresiones corporales y en un estricto y limitado catálogo de palabras injuriosas».

4. De acuerdo con las afirmaciones de Serra (1969, p. 58), «las Partidas interpretaban erróneamente esta equivalencia, puesto que en el Derecho Romano la "iniuria" se refería esencialmente a la acción judicial que preservaba del hecho antijurídico, en la que se incluía la deshonra. Este último aspecto constituirá, como bien sabemos, el núcleo del concepto medieval ("conducta realizada contra el honor u honra de las personas")».

5. En latín se dice «si algún varón o mujer hiriese, con efusión de sangre, a un vecino casado o a una mujer casada, pagarán sesenta sueldos y si no hay salida de sangre, treinta. Si algún varón o mujer llevados de lascivia, agarrase a un hombre casado por los cabellos, por las barbas o por los testículos, salve su puño (mano, instrumento del delito: se observa limitación de conceptos y tendencia al talión) con la pena equivalente al medio homicidio y, si no pudiere pagar, permanecerá en la cárcel treinta días, tras los cuales será apaleado de una parte de la villa a la otra. Y si algún hombre o mujer hiriere a varón - hembra, no casados pero con salida de sangre, pagará diez sueldos y si la sangre no brota, sólo cinco» (Serra, 1969, p. 84) 
Por su parte, las ofensas verbales, a las que las Partidas denominan injuria de palabra, recorrerán, bajo una formulación léxica precisa, muchos de los fueros municipales, pero habrá que esperar hasta la redacción del Fuero Juzgo (h 1241), traducción romance del Liber ludiciorum, para que el derecho medieval legisle en contra de los usos verbales infamantes, que continuarán ciñéndose a una nómina cerrada de palabras y expresiones injuriantes, a saber: podrido de la cabeza o de la serviz, tiñoso o gotoso, vizco, toposo, deslapreado, circunciso o señalado, corcobado y sarrazin ${ }^{6}$, presentes ya en esencia en las normas locales.

En los agravios recogidos por estos fueros municipales y, en especial, por el de Cuenca (h 1189), la mujer aparecerá como receptora del delito de injuria verbal7, materializado este, según hemos visto ya, en varios términos codificados entonces como denuestos $^{8}$ : puta, rocina o malata» ${ }^{9}$, ampliados en Usagre con ceguledora ${ }^{10}$ -ençeguladera en el de Coria-, rozina y monaguera. Con pequeñas modificaciones, los fueros leoneses coincidirán con los castellanos en esta enumeración y, sobre todo, en la protección de la honra y el honor femeninos. En otras recopilaciones, las menos, como la de Viguera y Val de Funes (c 1250), se denunciará a la mujer como agresora verbal y se aplicará una pena específica, diferente de la masculina: «Et si muger alguna dixiere mala palaura por vna vez o dos pierda la lengoa»"1.

En definitiva, la realidad social obligó a la consideración jurídica, tanto local como general, de la mujer, que podía funcionar como agresora o agredida de un delito que había tardado tiempo en ser reconocido como tal.

\section{EL IDEAL LINGÜÍSTICO (FEMENINO) Y EL ESTEREOTIPO: PRECEPTIVAS, TEXTOS DOCTRINALES Y JUICIOS METALINGÜÍSTICOS}

El comportamiento ofensivo derivado de un uso lingüístico inadecuado no contará únicamente con la sanción legal; los preceptos de los textos medievales y renacentistas, afanados en determinar las cualidades que debían acompañar el ideal

6. Serra distingue entre el primer período de la injuria (fáctica o de comisión por acción) del segundo (oral en convivencia con la fáctica) y, dentro de esta última, se refiere a una primera subfase, a la que pertenece el Fuero Juzgo, que admite la exceptio veritatis: «e aquel a quien lo dize no lo es...» (Serra, 1969, p. 77). 7. «Tan pronto la vida se reposa y cuenta en ella la calle, la casa, el mercado, la feria, la ida y vuelta a la iglesia, la reunión y el vivir social, la mujer da un sesgo a la convivencia, al honor del hombre y, consecuentemente, a la injuria» (Serra, 1969, p. 112).

8. El término más general en la Edad Media para designar las palabras inconvenientes, que traduce la contumelia latina: «Ningún siervo, maguer que sea bueno, non deve denostar... E si el siervo fuere vil, reciba L. azotes. E si el omne libre, o noble o de grand linage fizo al siervo... tal cosa por que lo denostase...» (Fuero Juzgo, libro VI, título IV, ley VII).

9. En el Fuero de Iznatoraf, cuya vinculación con el Fuero de Cuenca es conocida, se mencionan como denuestos contra la mujer puta, rocianada y gafa; además se alude la condición de que la palabra injuriosa se dirija «a mujer ajena» (Serra, 1969, p. 112). Evidentemente, esta condición implica que se trate de injuria proferida por un hombre.

10. Ver, para todos estos datos, Serra, 1969

11. Ver Segura, 2006, p. 157, n. 40. 
masculino y femenino, rechazarán asimismo las palabras inconvenientes, especialmente en su caracterización del discurso femenino.

En realidad, la consideración de la injuria verbal como delito, que acabamos de referir (§1), refleja, además del contexto social, la desviación que aquella representaba sobre el ideal lingüístico descrito en tratados doctrinales, en gramáticas y metalingüísticamente aludido en los textos literarios. Es decir, los escritos prescriptivos ${ }^{12}$ alentarán, lógicamente, el buen hablar, que, como comportamiento sociolingüístico, contaba con sobradas referencias en la descripción del palaçiano medieval o del cortesano renacentista.

Tal como quedó demostrado por González Ollé (1999), la lengua correcta, entendida como aquella a la que corresponden la claridad y la concisión y las palabras hermosas y apuestas, frente a las desapuestas o cazurras ${ }^{13}$, se vincularía en las épocas media y moderna con la corte:

Ca las palabras que se dizen sobre razones feas, e sin pro, e que no son fermosas, nin apuestas al que las fabla, nin otrosi al que las oye, nin puede tomar buen castigo, nin buen consejo, son ademas, e llámanlas cazurras, porque son viles, e desapuestas, e non deben seer dichas á homes buenos, quanto mas en decirlas ellos mismos, e mayormente el Rey (Partidas, Segunda Partida, título IV, ley II).

A este ideal lingüístico cortesano acompañaban, asimismo, las indicaciones sobre los elementos paralingüísticos poco afortunados, advirtiendo contra la desapostura en el hablar ${ }^{14}$, que debía evitarse en la elocución adecuada:

Ca segund dixieron los sabios que fablaron en esta razon estonce es buena la palabra et viene a bien quando es verdadera et dicha en el tienpo et enel lugar do conuiene. E apuestamente es dicha quando non se dice á grande[s] bozes nin otrosi muy baxo nin mucho de priesa ni muy de vagar et diciéndola con la lengua et non mostrándola con los mienbros faciendo mal contenente con ellos assi commo moviendolos mucho a menudo, en manera que semejase á los onbres que mas se atreven á mostrarlo por ellos que por palabra, ca esto es grand desapostura e mengua de razon (Partidas, Segunda Partida, título VII, ley VII).

12. Como han mostrado la amplia nómina de estudios sociales e históricos sobre la normativización del comportamiento femenino en la Edad Media y Moderna, proliferaron los tratados moralistas que establecían el modelo de perfección que toda mujer debía procurar. Desde la concepción de la mujer como depositaria en última instancia del honor y de la honra matrimonial y familiar, los tratados doctrinales ejercerían el control necesario para la preservación de estos valores sociales. Para un recorrido sobre el ideal femenino establecido por los moralistas, ver, entre otros, Pérez Molina et al., 1994, Candau, 2007 y Zapatero, 2007. Interesan a este propósito, especialmente, los artículos de López-Cordón, 1994, Morant, 2005, Ruiz Ortiz, 2014a y Candau, 2015.

13. «Vale también en lo antiguo lo mismo que descompuesto, feo y vill» (DA, s. v.). Para Covarrubias ejemplo de palabras cazurras sería «nombrar el miembro genital de uno y otro sexo». Corominas ofrece como significado común de este término en los siglos XIII y XIV 'descompuesto, desvergonzado, impropio para que lo vean u oigan mujeres', basándose en el Libro de Buen Amor (DCECH, s. v. cazurro). 14. Ver Cano, 2010, p. 7. Cito por el documento en PDF disponible en la red (ver Bibliografía). 
Entre las palabras inconvenientes o desconvenientes podíamos encontrar, según el Rey Sabio, las referidas a «los contenidos del enunciado» y las quebrantadoras de la cortesía social: «la excesiva alabanza del emisor por sí mismo y el hablar mal de aquellos a quienes se debe respeto porque al proceder de ellos se encuentran en nivel superior, o porque lo están en la jerarquía social (Dios, los santos, los reyes, los nobles, los ancestros)»15. Esta segunda manera de palabras desconvenientes, esto es, el insulto o denuesto, poseerá, como advierte el código alfonsí, un efecto perlocutivo que ya de entrada desaconsejaba su uso, sin necesidad de considerar aspectos como la veracidad o la apostura de lo dicho ${ }^{16}$.

Así pues, a juicio medieval, el criterio fundamental de variación se refería a la estratificación social, que distinguiría claramente entre las clases bajas y rústicas, que emplean palabras "cazurras» y «viles», y las cortesanas, integradas por los hombres «buenos y enseñados» - los de palacio: los reyes y la nobleza ${ }^{17}$-, lingüísticamente caracterizados por el empleo de palabras «buenas»y «apuestas» ${ }^{18}$. Esta distinción, que, de acuerdo con el planteamiento de D. Romagnoli, opone la rusticitas a la curialitas, civilitas y urbanitas ${ }^{19}$, constituirá la base del ideal lingüístico durante toda la Edad Media y los siglos posteriores ${ }^{20}$. En esta caracterización ideal no se atendería a la variación de género, que se entendía incluida, por tanto, en la social ${ }^{21}$.

Tal abstracción encuentra, sin embargo, en numerosas ocasiones rasgos que separan -más bien deben separar- el discurso masculino y femenino. Del mismo modo que se ha constatado para las disposiciones legales, que debieron incluir la referencia explícita a la mujer como reflejo de la realidad social, los textos doctrinales y todos aquellos de afán propedéutico y moralizante acogerán instrucciones en este mismo sentido, referidas al uso femenino.

Lo cierto es que, junto al ideal cortesano y a las disposiciones generales sobre la lengua, se encuentran especificaciones que han alimentado durante siglos el tópico del rechazo, propio y ajeno, de las mujeres como emisoras del comúnmente Ilamado «lenguaje vulgar»22, que alcanza, asimismo, indicaciones prosódicas:

15. Aclara Cano que estas palabras desconvenientes «no quieren decir lo que parece traducir su forma léxica, las "no derechas" en verdad y "no apuestas" en bien decir» (Cano, 2010, p. 9).

16. Ver Cano, 2010, p. 9.

17. Para la confluencia de paladino y palaciano, ver González Ollé, 1999 y Cano, 2010.

18. «Queda así fijada una radical oposición entre el uso lingüístico cortesano y cualquier otro ajeno a él» (González Ollé 1999: 208). Ver González Ollé, 1999 y Cano, 2010, pp. 12-13.

19. Ver González Ollé, 1999, p. 209

20. González Ollé (2002) realiza un extraordinario recorrido por los testimonios que apoyan esta idea.

21. Coates (2009, p. 39) recuerda a este propósito el fragmento del drama Enrique IV en el que se comprueba cómo se entrecruzan los dos aspectos: cuando «Hotspur se burla de su esposa, por su refinada manera de maldecir», diciéndole «iJuras como la mujer de un confitero! "La tuya no, palabra"; y "tan cierto como mi vida"; y "que Dios me perdone"; y "más claro que el día"; y vistes de tafetán tan delgado tus certezas, como si nunca hubieras ido más allá de Finsbury. Júrame, como dama que eres, Kate, con un buen juramento a buena boca; y déjales tu "palabra" y tus protestas de pimienta y de jengibre a los guardias vestidos de terciopelo y a los endomingados burgueses» [Enrique IV, primera parte, acto III, escena 1]. 22. No entramos aquí en otro tipo de tópicos, que cuentan asimismo con abundantes testimonios, sobre la doblez característicamente femenina en el uso de la palabra: «tengo por la mayor de mis desgracias 
Parece muy bien en una mujer la habla agraciada, la voz no varonil, bronca, recia que descalabre, sino el tono suave, delgado, amoroso, que regale el oído y se pegue al corazón. Eso es eloquitun tumm dulce (fray Alonso de Cabrera, De las consideraciones sobre todos los evangelios de la Cuaresma, a. 1598, CORDE [consulta: 15-04-2018]) ${ }^{23}$.

De hecho, la desapostura de palabra se considera uno de los peores defectos en la mujer. Cuando fray Bernardino de Sahagún alude a la mala condición de las mujeres nacidas bajo el décimo séptimo signo, las define de este modo:

Y si era mujer la que nacía en este signo, también era mal afortunada. No era para nada, ni para hilar, ni para tejer, y boba y tocha, risueña, soberbia, bocinglera; anda comiendo tzictli, y será parlera, chismera, infamadora. Sálenle de la boca las malas palabras como agua, y escarnecedora; es holgazana, perezosa, dormilona (fray Bernardino de Sahagún, Historia general de las cosas de Nueva España, 1576-1577, CORDE [consulta: 15-04-2018]).

Por tanto, el ideal lingüístico cortesano al que nos referíamos más arriba habría alimentado el estereotipo cultural de la mujer que rechaza la vulgaridad lingüística y no la ejerce en ningún caso; hasta tal punto se ha entendido de este modo que, en la sociedad europea, el hijo de un caballero debía ser educado por mujeres que no permitieran que se dijera «palabra alguna que pueda ser licenciosa o impura» en presencia del menor ${ }^{24}$, en tanto que este rasgo se asumía como propio del comportamiento lingüístico masculino ${ }^{25}$.

Estos lugares comunes, que se perpetuarán hasta la época actual, estarán presentes también en los estudios lingüísticos ${ }^{26}$. Robin Lakoff (2004), en sus afirmaciones sobre la diferente forma de maldecir de hombres y mujeres, daba por

y siento en el alma que, habiéndome mi dama entretenido con falsas esperanzas y promesas vanas, que nunca daría sus favores a otro, antes por premio de mi constante amor se casaría comigo, de que me dio su palabra, o fueron palabras de mujer o fueron obras de mi corta fortuna, pues, cuando me vio gastado y pobre, olvidada de todo lo pasado, dándome de mano la dio a otro, desposándose con él» (Mateo Alemán, Segunda parte de la vida de Guzmán de Alfarache. Atalaya de la vida humana, 1604, CORDE [consulta: 15-09-2017]).

23. «La idea de que el lenguaje de las mujeres es más cortés, más refinado -en una palabra: más femenino-, es generalizada y se ha mantenido vigente durante muchos siglos» (Coates, 2009, p. 37). Resulta evidente que esta afirmación pertenece al nivel universal del saber hablar, esto es, responde a una concepción universal por encima de las lenguas históricas: «La vulgaridad es un constructo cultural y la evidencia sugiere que cuando la nueva tradición cortesana de la Edad Media creó el refinamiento, también dio origen a la vulgaridad» (Coates, 2009, p. 37). Sirva como ejemplificación de esta afirmación el proverbio estadounidense que recoge Coates en su monografía: «A whistling sailor, a crowing hen and a swearing woman ought all three to go to hell together [Un marinero que chifla, una gallina que cacarea y una mujer malhablada, los tres deberían irse juntos al infierno]». Intentaremos comprobar cómo se materializa esta idea en el nivel histórico de nuestra lengua.

24. Coates (2009, p. 39) entresaca esta afirmación del manual The Governor (1531), de T. Elyot.

25. Este mismo manual del gobernante «para evitar que el niño escuche este tipo de palabras exhorta a que se impida la entrada de cualquier hombre a las habitaciones infantiles» (Coates, 2009 p. 39).

26. En Tabernero, (2018b) se recogen afirmaciones y estudios lingüísticos sobre este tema. 
sentado que las mujeres, «expertas en el arte del eufemismo» ${ }^{27}$, no emplean expresiones descorteses ${ }^{28}$.

Lindan estos estereotipos con otro comúnmente asentado que se refiere a la cortesía como rasgo femenino, distinción provocada, según el análisis sociolingüístico y pragmático, por el grado de empatía propio de cada sexo: las mujeres parecen presentar una sensibilidad mayor ante la imagen del otro en tanto que no sucede lo mismo con los hombres, de talante más práctico ${ }^{29}$.

En el extremo opuesto, en cambio, abunda en los textos desde la Edad Media la imagen de la mujer como especialmente proclive a algunos de los denominados «pecados de lengua»30 - «El otro pecado de la lengua es denostar delante alguna persona asi como falso, quando dize: "Vos sodes tal \& fi de tal" \& "vos fezistes tal cosa". E si dize mentira es asi como falso testimonio» (Martín Pérez, Libro de las confesiones, 1312-1317, CORDE [consulta: 20-03-2018])-, entre los que se cuenta la difamación. De hecho, como recoge Iván Jurado ${ }^{31}$, los tratados doctrinales de la Edad Media, como la Traducción del Libro de las donas (1438) de Francesc de Eiximenis, cuando dice:

Segundamente, peca el onbre por la lengua mal fablando \& murmurando \& disfamando a su prósimo. E este pecado es grande \& contra caridat, el qual faze mucho mal en el mundo, el qual Nuestro Señor Dios pena muy mucho: este pecado rreyna mucho en las mugeres, que non cuydan que fazen mal fablando mal de otrie \& de poner vna grant infamia, e jamás non fazen vna satisfaçión; antes mueren con todo este cargo que confiésanse de suso, \& de suso \& los confesores non lo escodriñan bien \& el vno daña al otro, que, commo dixo Ihesuchristo, «sy vn onbre çiego quiere guiar a otro çiego, amos caen en la foya» (traducción del Libro de las donas de Francesc Eiximenis, CORDE [consulta: 19-04-2018]).

Qüistión fazen algunos el pecado de la lengua sy deue estar con los pecados mortales o con los çinco sesos corporales; e dizen que por todo ha logar segunt diuersos entendimientos, porque, pues non lo auemos ençima tocado, aquí fablaremos vn poco. E deués saber que esta materia es mucho nesçesaria a las

27. Coates reflexiona a propósito de estas afirmaciones de Lakoff y de otras anteriores de Jespersen, que estos autores ofrecen como comprobaciones científicas, como descripción de un ideal lingüístico antes que verdad científicamente contrastada: «la verdad es mucho más compleja de lo que sugiere la lingüística folclórica» (2009, p. 41). Remitimos en este punto a las cuestiones que antes apuntábamos sobre la definición medieval y renacentista del ideal lingüístico.

28. Ver Coates, 2009, p. 40

29. Coates (2009, p. 180) resume estos principios. Cabe recordar aquí la teoría de la cortesía y de la imagen positiva y negativa de Brown y Levinson, necesaria para el estudio del insulto desde la perspectiva lingüística. Ver, a este propósito, Tabernero, 2018a y b.

30. Para esta cuestión, ver Chauchadis, 2004.

31. Jurado, 2014, pp. 189-194. 
mugeres, que en espeçial han acostunbrado mucho a pecar en la lengua ${ }^{32}$ (traducción del Libro de las donas de Francesc Eiximenis, CORDE [consulta: 1904-2018]) $)^{33}$,

o el Jardín de nobles doncellas (1468) de fray Martín de Córdoba, junto con los personajes femeninos de la literatura del momento, el Corbacho (1438) o la Celestina (1499), entre otros, contribuyeron a la consolidación del prototipo de mujer parlera y deslenguada heredado de la Antigüedad, que promoverán en los años posteriores, ya con el cambio de siglo, las enseñanzas de Juan Luis Vives en su De Institutione Feminae Christianae (1523) ${ }^{34}$, las del doctor Huarte de San Juan en su Examen de ingenios (1575), las páginas protagonizadas por el pícaro Guzmán de Alfarache o por La pícara Justina y la cultura popular reflejada en el refranero ${ }^{35}$.

Asentada estaba, por tanto, desde época temprana la idea de la afición femenina a «mal dezir», al igual que el efecto perlocutivo diferente provocado en virtud del sexo del receptor; esto es, la reacción ante el denuesto o la injuria verbal diferencia también a hombres y mujeres ${ }^{36}$ («pensé que era pulla y respondiles con estremada cólera, ca la de las mujeres es siempre de Estremadura», Pícara, p. 701). De este modo hacía constar la pícara Justina su propia reacción ante lo que ella interpreta como insultos de tres romeras:

De las palabras que me dijeron no hago caso, porque entre mujeres esto de palabras, por donde se van se vienen. Los hombres, como son sólidos y macizos, en echando una palabra de la boca de uno a otro, se les torna a ella la injuria, que como encuentra en duro, torna de rebote; mas las mujeres diz que andamos muy barrenadas, y así, las palabras que nos decimos no han llegado de una para otra cuando colan tierra. Y aun dicen que, conforme al libro del duelo del género femenino, palabras de mujer a mujer no cargan. Debe de ser que pesan menos y son hechas de aire colado. $Y$ aun dicen que dichos de mujer a hombres se desquitan con dar una carrera por su calle o darlas paz de Francia. Lo que yo sé de uso es

32. En los procesos del corpus encontraremos descripciones de injuriadoras que encajan con esta descripción: «mujer de muy mala lingua y que murmura y habla muy mal de cualesquiera personas deshonrrándolas y publicando cosas contrarias a la buena reputación de ellas» (1643).

33. Pueden consultarse citas de Huarte de San Juan, de fray Martín de Córdoba, del Corbacho o de la Celestina en Archer, 2001 y en Jurado, 2014. Ver también el estudio de Martínez Góngora, 1999.

Evidentemente, mención aparte merecerían entre la literatura didáctico-moral los manuales de confesores redactados entre los siglos XVI y XVIII, especialmente algunos de los más representativos, como el del padre Martín de Azpilcueta; sin embargo, los pecados de lengua se refieren exclusivamente en estos casos a los que atentan contra el segundo mandamiento, esto es, la maldición y la blasfemia, cuya naturaleza teológica y moral los separa claramente del uso del insulto que contemplamos en estas páginas. Ver, para la distinción, Tabernero, 2010. Para la repercusión social de la blasfemia, ver Usunáriz, 2005b. 34. Jurado (2014, pp. 196-197) habla también de Francisco de Osuna, de fray Luis de León o de Antonio de Guevara, que, como Juan Luis Vives, alaban el silencio en la mujer y denuestan a la parlera y deslenguada, características que identifican a la desvergonzada.

35. Ver Martínez Garrido, 2001, Fernández Poncela, 2002 y Jurado, 2014.

36. Advierte al inicio de este número el autor de la Pícara «Que la guerra y la paz de las mujeres/ anda presa con puntas de alfileres» (Pícara, p. 700). 
que entre nosotras aquella queda cargada a quien le quedare o por corta o mal echada (Pícara, pp. 702-703).

\section{[...]}

Ya que se apaciguó el pleito y se fue el diablo para ruin, y nos concertamos como buenas cristianas, fuímonos de camarada todas con tanta hermandad como si todas cuatro fuéramos mellizas. Este sí que es uso y no el de los hombres, que, por dos palabras que se digan cara a cara, se descaran para no verse la cara uno a otro en mil años ${ }^{37}$.

Según Justina, las mujeres gustan de discutir sobre «lo insustancial»; callan, por el contrario, ante las palabras viles -0 «nombres pascuales» ${ }^{38}$-, que son «injurias graves», propias de bravucones o «capitanazos»:

Igual lo paramos las mujeres, las cuales somos como arcos de cubas, que cuanto más rechina es señal que están más cerca de juntarse los estremos del aire, y ansí, mientras más rechinamos riñendo, más amistad nos hacemos, y aunque más nos carguen de injurias, no por eso hacemos más ruido, antes somos como carretas, que mientras más las cargan, menos ruido hacen. Las riñas de las mujeres son sobre si dejiste cipe o zape, y sobre si parece bien el hurraco, o sobre si arrastra la falda. Nunca reparamos en cosa sustancial, nunca reñimos injurias graves, que esas antes sirven de hacernos callar. Pardiez, mientras me dijeron de floreo, bravamente les reenvidé, mas en diciéndome dos o tres verdades que contenían la casa y nombres pascuales, callé como en misa. No nacieron las injurias graves sino para capitanazos (Pícara, pp. 702-703).

Aunque a partir del siglo XVIII asistiremos a un cambio del concepto de mujer, que ya no representará el desorden y la lascivia sino la inocencia y la pureza ${ }^{39}$, los textos seguirán insistiendo en un ideal femenino contrario a la mujer malhablada y «vecera de mal decir»:

Si tiene razón, la pierde desde el momento que la hace valer con altanería y palabras feas; que la razón de una mujer no se reconoce ni se atiende sino acompañada de suavidad y dulzura. La fuerza de la mujer está en la dulzura, en la suavidad, en la prudencia, en ser resignada y paciente. Impone su voluntad suplicando, triunfa de rodillas. Las amenazas de una mujer hacen reír á los hombres, y hay pocos que no se conmuevan con sus lágrimas.

[...] Y por el contrario, iqué repulsión inspira la mujer deslenguada y altanera que con voces y denuestos pretende imponer su voluntad! iQué mala idea se forma de ella, y cómo inspira la de negarle justicia aunque la tenga, por el modo

37. Y continúa: «Por gran loco fue tenido el que dijo que quería hacer un soterraño en que guardar el aire del invierno para el verano, como la nieve, pero por más locos tengo a los hombres que guardan las palabras de diez en diez años, que, pues las palabras son aire, quien las guarda, guarda aire» (Pícara, pp. 704-705).

38. Mañero (Pícara, p. 706, n. 137) remite a Autoridades y a Correas para la expresión «decir los nombres de las Pascuas», esto es, los términos injuriosos por antonomasia: bellaco, puta, alcahueta; en definitiva, 'injuriar'.

39. Ver López-Cordón, 1994, pp. 105-106 
de pedirla, y cómo en lugar de convencer irrita al que pretende aplacar! Y á la verdad no es extraño que la mujer mal hablada y colérica repugne, porque es muy repugnante. [...]

Convenceos, hermanas mías, de que la honestidad y la moderación en las palabras es tan precisa como en las acciones; que la mujer que no pone coto á su lengua, está perdida. Así como su felicidad depende de su virtud, su fuerza y su poder dependen de su prudencia y de su dulzura (C. Arenal, Cartas a los delincuentes, 1885, CORDE [consulta: 15-04-2018]).

De hecho, los historiadores que han analizado la creación y propagación de esta imagen sobre la mujer ${ }^{40}$, ya ser abyecto y depravado, ya puro y débil, han mostrado de forma evidente la función de todos estos escritos, doctrinales o de ficción, como prueba de la necesidad de un control masculino sobre este grupo y justificación, en definitiva, de la superioridad del hombre.

\section{LA VIOLENCIA VERBAL FEMENINA EN LA REALIDAD COTIDIANA}

Junto a las referencias textuales mencionadas (§2), también las transcripciones de litigantes y testigos de la documentación jurídica de estos siglos de la Edad Moderna revelan la mayor frecuencia del intercambio de insultos entre interlocutores del mismo sexo. Según los datos extraídos de nuestro corpus ${ }^{41}$, los hombres insultan preferentemente a otros hombres y las mujeres, a otras mujeres ${ }^{42}$. En el caso de los primeros, además, resulta socialmente censurable poner la voz en mujer ajena: «Nengún hombre de bien toma palabras con mujeres y todo hombre sea cortés con las mujeres y nenguno ponga lengua en las mujeres ajenas ${ }^{43}$ » (1533).

40. Ver López-Cordón, 1994, Pérez Molina et al., 1994, Ortega, 1999, Morant, 2005, Candau, 2007 y 2015 , Gil Ambrona, 2008, Pérez Molina, 2004, Ruiz Ortiz, 2014a y 2014b o Jurado, 2014, entre otros.

41. El corpus del que se han obtenido estos datos, procesos judiciales por injurias de los siglos XVI y XVII archivados en Navarra, nos ha servido como base de estudio en varios trabajos anteriores sobre el insulto. Se puede encontrar una descripción de este corpus en Usunáriz (2017, pp. 68-69): «las investigaciones que hemos realizado en los fondos del Archivo General de Navarra reflejan esa "realidad onmipresente" del denuesto, con más de 4.100 procesos por injurias, de los cuales hemos estudiado a fondo más de 1.400, circunscritos a los siglos XVI y XVII». De estos procesos se han entresacado, como material de análisis de este trabajo, las declaraciones de los encausados y de los testigos para reconstruir los intercambios de insultos, teniendo en cuenta el sexo del emisor y del receptor.

42. Ver Tabernero, 2018b, para el uso de términos injuriosos según la variable sexo.

Para el empleo de los pleitos por injurias como fuente de conocimiento de la realidad cotidiana en las diferentes épocas, ver el estado de la cuestión en las primeras páginas del artículo de I. Jurado, 2015, pp. 677-682. Aunque, como sucede en el caso de la Historia (ver Ruiz Astiz, 2010, pp. 14-15), también desde el estudio histórico de la lengua pueden plantearse reservas a la validez absoluta de los pleitos judiciales como fuente, la bibliografía lingüística correspondiente ha validado ampliamente su fiabilidad en este ámbito en cuanto testimonio del uso de los hablantes de la época en cuestión.

43. Como se constata en los textos legislativos medievales, la consideración de la mujer casada es diferente a la de otras mujeres, sobre todo en cuanto perteneciente a su marido, por lo que la defensa o el quebranto del honor de ella repercute directamente en el de él. En la instrucción de los procesos del corpus, en la parte correspondiente a la interposición de la queja, encontramos observaciones como la que sigue referidas al marido de mujer injuriada: aquel afirma que su mujer ha sido «muy ofendida e 
Evidentemente, en las épocas medieval y clásica existirían mujeres observadoras del estereotipo lingüístico femenino que se ha reflejado en las páginas precedentes, poco dadas al uso de palabras y expresiones injuriosas, aunque los estudios históricos sobre las fuentes documentales medievales y modernas han destacado el papel de la mujer como sujeto activo y pasivo de la injuria ${ }^{44}$, llegando incluso a tachar de femenino este crimen ${ }^{45}$.

En efecto, los testimonios recogidos más arriba (§2), con las advertencias de los mismos preceptistas y adoctrinadores sobre el gusto femenino por la maledicencia, nos ponen en la pista del uso común de otro tópico femenino, reflejado en la literatura, el de la mujer que agrede con la palabra, principalmente a otra mujer.

En este sentido, según se ha afirmado ya en otros trabajos sobre el uso de la realidad cotidiana, la ofensa funciona como niveladora social en la medida en que se trata de una característica femenina, y masculina, que no depende de la condición del hablante ${ }^{46}$. Es la codificación que adquiere la ofensa la que puede presentar, en ocasiones, diferencias según estratos y formación: las mujeres menos instruidas y de posición social menos elevada tienden en mayor número al uso de voces y expresiones infamantes, que conviene deslindar ${ }^{47}$ de las únicamente malsonantes, o juramentos, que proceden de las anteriores y se encuentran ya en un grado de lexicalización que les permite aparecer en el discurso sin cumplir una función apelativa. Se trata de dos aspectos de difícil delimitación, pues ambos poseen repercusión sociolingüística y los dos merecen consideración jurídica, aunque motivada por causas diferentes ${ }^{48}$.

Volviendo a los datos que ofrece el análisis del corpus de testimonios de procesos por injurias de los siglos XVI y XVII en Navarra ${ }^{49}$, los resultados previos de los que parte el estudio que se presenta en estas páginas advertían, en la línea de

atrozmente injuriada e yo como su marido que padecí e padezco la dicha injuria y me compete acusarla» (1552). Los estudios del insulto desde la perspectiva de la historia social del lenguaje han insistido precisamente en el alcance social de la ofensa, tanto en hombres como en mujeres, como destructor de la fama y reputación del injuriado (ver, entre otros muchos y para sociedades diferentes, Undurraga, 2012; Candau, 2016, pp. 73-75). Interesantes a este respecto resultan los anexos sobre el perfil social de los injuriados y la codificación léxica de las injurias del XVIII chileno en Undurraga, 2012, pp. 387-391. 44. Según Jurado (2014, p. 198), «el modelo de mujer predicado por los moralistas estaba lejos de la realidad». A estas mujeres que, de un modo u otro, quebrantan los preceptos o el concepto de ideal femenino las denomina este autor «transgresoras».

45. F. Segura (2006: 168 y n 88) se refiere también a estos estudios y presenta el caso de Navarra como contrapunto en el sentido de que en esta zona el análisis documental no permite reafirmar esta idea. Ver, para otros datos, Mendoza, 1999. Para el Chile del siglo XVIII, ver Undurraga, 2012.

46. Precisamente en sentido contrario a esta nivelación apuntan los estudios sobre el insulto en la literatura áurea; el uso de términos y expresiones ofensivas obedece en la ficción a un orden social establecido e inquebrantable. Ver para la contraposición entre la literatura y la realidad cotidiana, Tabernero, 2013 y Usunáriz, 2017. Para la transgresión en la realidad cotidiana, ver Jurado, 2015.

47. Ver Tabernero, 2018a.

48. Téngase en cuenta que la costumbre de proferir juramentos contraviene hondos presupuestos teológicos (ver Tabernero, 2010).

49. Ver Tabernero, 2018b. 
las afirmaciones que realiza Justina (\$2), de un predominio del uso masculino del insulto, en una proporción del $62 \%$ frente al $38 \%{ }^{50}$, al tiempo que se muestra cómo, de acuerdo con el uso social establecido, en los intercambios de insultos se prefiere a alguien del mismo sexo como interlocutor -en el caso de las mujeres, en un 63\% de ocasiones se interpela a otra mujer y en un $37 \%$ a otro hombre; los hombres insultan a otros hombres en un $70 \%$ de las veces y solo un $30 \%$ a otras mujeres ${ }^{51}-$.

Analizamos en ocasiones anteriores la diferente materialización léxica en virtud del sexo del emisor, teniendo en cuenta asimismo si el interlocutor era hombre o mujer, lo que nos permitía obtener resultados importantes sobre la consideración de cada uno de los sexos en la época analizada y su diferente comportamiento lingüístico ${ }^{52}$.

Como continuación de este análisis, nos interesa ahora centrarnos en la interacción y en la reacción que provocan los insultos en hombres y en mujeres cuando el agresor verbal es una mujer ${ }^{53}$.

En la mayoría de los casos, a la mujer demandada por injuriadora se le atribuyen, con mayor frecuencia que al hombre, hábitos lingüísticos poco recomendables:

vecera de maldecir, reñir y revolver en el barrio con cuantos vive en aquel, e de mala lengua e maldiciente $(1515)^{54}$ $(1527)^{55}$

se suele desmandar de su lengua e suele ser causa de riñas y cuestiones deslenguada y boquirrota y ultrajosa de palabras y obras (1542) ${ }^{56}$

mujer muy soberba y deslenguada y vecera de deshonrar a quien quiera $(1550)^{57}$

soberba y de mala lengua $(1554)^{58}$

50. Se ofrece el detalle de estos datos en Tabernero, 2018b.

51. Aunque la diferencia no resulta estadísticamente significativa y puede deberse a la incidencia de otros factores, recordaremos que, según el estudio ofrecido en Tabernero, 2018b, el porcentaje de hombres que insultan a mujeres es proporcionalmente menor que el de mujeres que injurian a hombres. En este artículo se atiende, además, a la semántica de los insultos como manifestación de los valores sociales en uso, elemento de consideración imprescindible en el estudio de este tema.

52. Ver Tabernero, 2018b

53. Aunque elementos imprescindibles de consideración en el análisis de la trascendencia social del insulto, no nos ocupamos en esta ocasión de agravantes como la publicidad de la ofensa o el perfil social del destinatario, que se han contemplado en otros trabajos (ver Tabernero, 2018a y b). El interés en este caso se centra en el propio acto de habla y, en consecuencia, en la emisión y respuesta de los intervenientes en la ofensa. En cualquier caso, para la repercusión social de la injuria en la sociedad navarra del XVIII, puede verse Maiza, 1992.

54. Archivo General de Navarra [AGN], Tribunales Reales. Procesos, núm. 262843.

55. AGN, Tribunales Reales. Procesos, núm. 8541.

56. AGN, Tribunales Reales. Procesos, núm. 209905.

57. AGN, Tribunales Reales. Procesos, núm. 950.

58. AGN, Tribunales Reales. Procesos, núm. 144502. 
soberbia y muy rijosa y deslenguada $(1558)^{59}$

[Graciana era] ${ }^{60}$ soberbia, revoltosa y vecera de reñir con todos sus vecinos sin propósito alguno y muy deslenguada, acostumbrada a infamar a personas de honrra $(1560)^{61}$

mujer recia y vecera de reñir y maltratar de palabras a muchas personas de arte y calidad y por el contrario mi parte es mujer de buena vida, fama y conversación y pacífica, que vive bien y honestamente, casada con su marido, sin que tenga con ningunos cuestiones ni barajas $(1560)^{62}$

mujer vecera y acostumbrada a ultrajar y deshonrar hombres y mujeres con su lengua $(1575)^{63}$

está notada de ocasionada y mujer habladora (1642) ${ }^{64}$

arrojada en su modo de hablar (1642)

A los hábitos lingüísticos inconvenientes acompañaban generalmente otras características no menos inadecuadas. A María de Inza, por ejemplo, una de las imputadas por delito de injuria, se la describe como «deslengoada y boquirrota y ultrajosa de palabras y obras» $\mathrm{y}$ «persona de mal vivir e intolerable, que no hay quien la ose hablar ni tener con ella conversación»:

por ser tal, su marido Joanequi de Beteleu, portero real, la tiene desechada y apartada de su cohabitación, consorcio y vida maridable y también por haber sido y ser la dicha acusada mala de su persona y adúltera, que ha tenido aceso y cópula carnal, estando casada con el dicho su marido, a clérigos, soldados y otra manera de gente. Y lo mesmo hacía en vida de Bernat de Burguet, su primer marido, y ha seido y es toda tan disoluta y pródiga que ha perdido su fama y hacienda en sus vicios y maldades $(1542)^{66}$.

Además, las mujeres emplean, siempre según estos testimonios documentales, elementos paralingüísticos que contravienen punto por punto los usos convenientes dictaminados en los tratados y disposiciones medievales y posteriores: las voces altas, los gritos, los gestos - no nos referiremos en este momento a los gestos de significado verbal-y, en muchas ocasiones, la agresión física como acompañamiento de la verbal:

59. AGN, Tribunales Reales. Procesos, núm. 281002.

60. Incluyo entre corchetes las palabras que no constituyen transcripción textual de las fuentes documentales.

61. AGN, Tribunales Reales. Procesos, núm. 86773.

62. AGN, Tribunales Reales. Procesos, núm. 86773.

63. AGN, Tribunales Reales. Procesos, núm. 281513.

64. AGN, Tribunales Reales. Procesos, núm. 123134.

65. AGN, Tribunales Reales. Procesos, núm. 123134.

66. AGN, Tribunales Reales. Procesos, núm. 209905.

En otros casos, se habla de «mujer deshonesta y de mal vivir y que hace maleficio de su persona con muchos» (1552). 
bellaca acuchillada y que fuese a su abogado con un par de manzanas para que le ganase su pleito, señalando con el dedo las narices y la cara, deciendo que era bellaca acuchillada (1529) 67

[María Diez atacó a María Juan de Labayen, dándole] muchas pugnadas y golpes en su persona $(1527)^{68}$

[cuando a altas voces, desde su ventana Graciana le dijo a Catalina] que era una vellaca puta y mala muger (1539) ${ }^{69}$

Basándonos ahora en la clasificación de la reacción o respuesta del injuriado propuesta en un trabajo previo sobre este mismo corpus ${ }^{70}$ (ver figura 1), se intentará comprobar en lo que sigue la representatividad de esta variable en el comportamiento de los injuriados. Se proponían entonces varios modos de reacción: negar (y devolver) la injuria (1); devolver la ofensa o intercambio de insultos (2); desmentir la afirmación del injuriante (3); no identificación con la ofensa y necesidad de comprobación del acto de habla (4); anulación de la función y el efecto de la injuria (5); reacción indirecta $(6)^{71}$.

\begin{tabular}{|c|c|c|c|c|c|c|}
\hline TIPOS & \multicolumn{6}{|c|}{ SUBTIPOS } \\
\hline $\begin{array}{l}\text { 1) Negar } \\
\text { (y devolver) la } \\
\text { injuria }\end{array}$ & $\begin{array}{l}\text { a. Negar } \\
\text { la injuria y } \\
\text { devolver otra } \\
\text { diferente. }\end{array}$ & $\begin{array}{l}\text { b. Devolver la } \\
\text { misma injuria } \\
\text { con la negación } \\
\text { respecto a su } \\
\text { persona. }\end{array}$ & $\begin{array}{l}\text { c. La nega- } \\
\text { ción de la } \\
\text { ofensa puede } \\
\text { expresarse } \\
\text { en términos } \\
\text { afirmativos. }\end{array}$ & $\begin{array}{l}\text { d. Negación o } \\
\text { vuelta } \\
\text { argumentada. }\end{array}$ & $\begin{array}{l}\text { e. Negación } \\
\text { afirmando } \\
\text { la cualidad } \\
\text { contraria } \\
\text { con identifi- } \\
\text { cación con } \\
\text { el emisor. }\end{array}$ & \\
\hline $\begin{array}{l}\text { 2) Devolver } \\
\text { la ofensa: } \\
\text { intercambio de } \\
\text { insultos }\end{array}$ & $\begin{array}{l}\text { a. Devolver la } \\
\text { misma injuria } \\
\text { con otras } \\
\text { añadidas. }\end{array}$ & $\begin{array}{l}\text { b. Devolver } \\
\text { con diferente } \\
\text { codificación. }\end{array}$ & $\begin{array}{l}\text { c. Devolver } \\
\text { otras injurias } \\
\text { con el verbo } \\
\text { callar. }\end{array}$ & $\begin{array}{l}\text { d. Afirmar } \\
\text { la ofensa y } \\
\text { devolución al } \\
\text { interlocutor. }\end{array}$ & $\begin{array}{l}\text { e. Recono- } \\
\text { cer la ofen- } \\
\text { sa e incluir } \\
\text { en ella al } \\
\text { interlocutor. }\end{array}$ & $\begin{array}{l}\text { f. Respon- } \\
\text { der con una } \\
\text { maldición. }\end{array}$ \\
\hline $\begin{array}{l}\text { 3) Desmentir la } \\
\text { afirmación del } \\
\text { injuriante }\end{array}$ & $\begin{array}{l}\text { a. Acusar al } \\
\text { injuriante de } \\
\text { mentir. }\end{array}$ & $\begin{array}{l}\text { b. Apelación a } \\
\text { la prueba de } \\
\text { verdad. }\end{array}$ & $\begin{array}{l}\text { c. Desmentir } \\
\text { con argumen- } \\
\text { tos. }\end{array}$ & & & \\
\hline $\begin{array}{l}\text { 4) No identifi- } \\
\text { cación con la } \\
\text { ofensa y necesi- } \\
\text { dad de compro- } \\
\text { bación del acto } \\
\text { de habla }\end{array}$ & $\begin{array}{l}\text { a. Identi- } \\
\text { ficación } \\
\text { fingida con la } \\
\text { ofensa. }\end{array}$ & $\begin{array}{l}\text { b. Comproba- } \\
\text { ción o referen- } \\
\text { cia al acto de } \\
\text { habla. }\end{array}$ & & & & \\
\hline
\end{tabular}

67. AGN, Tribunales Reales. Procesos, núm. 262929.

68. AGN, Tribunales Reales. Procesos, núm. 262909.

69. AGN, Tribunales Reales. Procesos, núm. 318032.

70. Ver Tabernero, 2018a

71. Estos seis modos de reacción se subdividían, a su vez, en varios subtipos, que recojo en la tabla que aparece más abajo. Para la descripción detallada de cada uno de ellos, ver Tabernero, 2018a. 


\begin{tabular}{|l|l|l|l|l|l|l|}
\hline $\begin{array}{l}\text { 5) Anulación } \\
\text { de la función y } \\
\text { el efecto de la } \\
\text { injuria }\end{array}$ & $\begin{array}{l}\text { a. Menos- } \\
\text { precio o } \\
\text { desprecio del } \\
\text { emisor. }\end{array}$ & $\begin{array}{l}\text { b. Distancia- } \\
\text { miento personal } \\
\text { de la ofensa. }\end{array}$ & & & & \\
\hline $\begin{array}{l}\text { 6) Reacción } \\
\text { indirecta }\end{array}$ & & & & & & \\
\hline
\end{tabular}

Figura 1. Clasificación de las respuestas masculinas y femeninas a la injuria, según Tabernero (2018a)

Analizados los datos que ofrecen los testimonios de los pleitos, se comprueba que las interacciones femeninas en los casos de agresión verbal se reparten de la siguiente manera (figura 2): el intercambio de insultos (grupo 2) resulta la opción preferida en el duelo femenino (69,6\%), seguido a distancia de la negación (grupo 1) $(20,3 \%)$ y de la desmentida (grupo 3$)(11,8 \%$ ); se observa asimismo algún caso de no identificación y comprobación mediante pregunta (grupo 4). No encontramos, en cambio, interacciones que se correspondan con el resto de los grupos (4 y 5) y, como veremos a continuación, tampoco en los casos recogidos tenemos muestra de todos los subtipos, que, aparecen, por el contrario, en las interacciones en las que intervienen los hombres.

\begin{tabular}{|l|c|}
\hline Grupo 2. Intercambio de insultos & $66,10 \%$ \\
\hline Grupo 1. Negación & $20,30 \%$ \\
\hline Grupo 3. Desmentida & $11,80 \%$ \\
\hline Grupo 4. No identificación y comprobación & $1,60 \%$ \\
\hline
\end{tabular}

Figura 2. Duelo verbal de mujeres

En los grupos 1 -negación (y devolución) de la ofensa- (figura 3) y 2 -intercambio de insultos - (figura 4), aparecen testimonios de todos los subtipos considerados, de forma más equitativa en el primer caso que en el segundo, en el que predomina (50\% de los casos) el subtipo $b$-el injuriado devuelve la injuria con diferente codificación (a veces con sinónimos) - frente al resto:

1. Grupo 1a (negación y vuelta diferente)

$\begin{array}{ll}\text { MARÍA } & \text { ¿De dónde vienes, borracha, con tus carrillos } \\ \text { MARÍA } & \text { Colorados? } \\ \text { MARÍA } & \text { Tú eres poy borracha. }\end{array}$


2. Grupo $1 b$ (negación)

JOHANA Calla, tú, mala escogida.

MARÍA Yo no soy mala escogida ni he ido nunca vestido el capote de lana tras los hombres. (1535) ${ }^{73}$

3. Grupo 1c (negación y vuelta con diferente codificación)

MARÍA Vieja ruin, que toda tu vida has sido ruin.

GRACIANA No soy yo vieja y ruin, pero tú eres jóvena y mala. $(1547)^{74}$

4. Grupo $1 d$ (negación y argumentación)

MARÍA

Ladrona vieja, traéis zamarra ajena, hurtada como ladrona.

[Constanza respondió que no era cierto, porque la había comprado.] (1554)75

5. Grupo 7e (negación indirecta)
MARÍA
Puta pública.

María contestó que si nunca se había de hartar de decir mal y le tiró un pedazo de ladrillo a la dicha María de Egozcue. (1563) 76

\begin{tabular}{|l|c|}
\hline b. vuelta y negación & $33,30 \%$ \\
\hline a. negación y vuelta diferente & $25,00 \%$ \\
\hline c. y e. negación o vuelta con afirmación o negación indirecta & $16,60 \%$ \\
\hline d. negación con argumentación & $8,30 \%$ \\
\hline
\end{tabular}

Figura 3. Grupo 1

6. Grupo 2a (devolver el mismo insulto y otros)

MARÍA Borrachas, putas, excomulgadas.

MARÍA JUAN Y SU HIJA Puta y ladrona y escomulgada. $(1542)^{77}$ 


\section{Grupo 2b (vuelta con diferente codificación)}

María ¿Cómo has venido, que ahí más palos te dieron que pan blanco? Yo bien sé una dueña para tú, si tú quieres...

MARíA Oh ruincilla, maldecienta, malilla perdida.

MARÍA MARTín ¡Oh cabrilla, vete a casa de Pedro Zardan! (1542) 78

8. Grupo 2b y e (diferente codificación) (reconocer e incluir al interlocutor)

[Beruete llamó a Olagüe en euskera] parlera charra, que quiere dezir parlera vieja, siempre estaréis riñendo, [a lo que Olagüe respondió] que ella era la parlera y que estaba en casa dada por Ortiz y que mejor era para gastar la hacienda que para ganar.

[Y a esto respondió Beruete:] como puta vieja del cantón has destar riñendo. $(1545)^{79}$

9. Grupo 2c («calla» y otras injurias)

MARÍA DE GUENDULÁIN Puta sucia, bellaca sucia, puerca sucia, borracha.

MARÍA LIZASO Calla, calla, que si vergüenza tuvieses callarías, oh doña puerca bellaca. $(1559)^{80}$

BERUETE Doña ruinacha, ¿no podéis callar? [en vascuence: quera una puta vieja].

OlAgüE Tú eres. ([que era una] puta charra, cantonera, que quiere decir puta vieja cantonera) (1545) ${ }^{81}$

10. Grupo 2d (negación con argumentación)

JUANA Fija mala y de mala madre.

MARÍA Ella es fija de tan buena madre como vos y vos no sois mejor que otra. $(1515)^{82}$

MARÍA Cosa mala.

Miguela Mira a tu cabeza. (1545) 83 


\section{Grupo $2 f$ (maldición)}

MARÍA Tú no tienes buena noche para dar, doña mala mujer.

Miguela Con malas cujaradas te saquen lo que tienes en la barriga. (1545) ${ }^{84}(2 \mathrm{f})$

\begin{tabular}{|l|l|}
\hline b. Devolver con diferente codificación. & $50 \%$ \\
\hline a. Devolver la misma injuria con otras & \\
añadidas. & \\
c. Devolver otras injurias con el verbo & \\
callar. & $50 \%$ \\
d. Afirmar la ofensa y devolución al & \\
interlocutor. & \\
e. Reconocer la ofensa e incluir en ella & \\
al interlocutor. & \\
f. Responder con una maldición. & \\
\hline
\end{tabular}

Figura 4. Grupo 2

En el grupo 3 -desmentida- (figura 5) están representados por igual los subtipos a -uso del verbo mentir- y c -desmentir argumentando- (42,8\%), al lado del subtipo $b$-exigencia de pruebas (14,2\%)-, y en el grupo 4 -no identificaciónaparece testimoniado únicamente, y de forma muy escasa, el subtipo b-comprobación o referencia al acto de habla.

12. Grupo 3a (mentira)

BERUETE [en vascuence] Ruin, cevil, de ruin gesto.

[Olagüe le replicó que] ella tiene tan buen gesto que Dios le hizo merced como ella.

BERUETE [en vascuence] Mentís, doña bellaca, puta, cantonera. $(1545)^{85}$

13. Grupo 3b (prueba de verdad)

ARTOLA Gaizco ezagutua ['mala conocida'].

BARAIBAR Tú has de probar de dónde me sabes más que yo no sé ni Dios me puede saber que yo sea mala.

ARTOLA Bai y aiz gaizto probatua ['Sí y sin duda mala probada']. (1529) 86 
14. Grupo 3c (argumentos)

MARÍA de LARRASOAÑA [MADRE] Esa mi hija ladronaza vieja me tiene mi piel desforrada escondida debajo las lanas que su marido hurtó.

[María de Aizcorbe (hija) le respondió] que ella no le tenía escondido sino que, habiéndolo empeñado la dicha su madre, juntamente con María de Echalecu lo abía redemido. $(1551)^{87}$

\begin{tabular}{|l|l|}
\hline a. y c. mentira y argumentos & $42,80 \%$ \\
\hline b. prueba de verdad & $14,20 \%$ \\
\hline
\end{tabular}

FIGURA 5. GRUPO 3

15. Grupo 4b (comprobación o referencia al acto de habla)

BARAIBAR [en vascuence] Algún día alguna novilla mejor que tú ha bajado por ahí.

CATALINA ¿Dices que soy mala?

BARAIBAR Yo no digo; así es. (1529) 88

En resumen, en las mujeres de nuestro corpus la ofensa verbal por parte de otras mujeres provoca, principalmente, una respuesta insultante de codificación léxica diferente, a la que siguen la negación y la desmentida, ligera variación sobre la anterior.

Así pues, se demuestra, por un lado, que su comportamiento en este caso no difiere del masculino ni parece tener en cuenta el sexo del interlocutor, ya que el tipo de reacción lingüística resulta similar frente a hombres y mujeres. Es cierto, sin embargo, que los datos obtenidos hablan de una variedad más amplia de tipos de respuesta en los casos masculinos, que no resulta significativa, creemos, dado que tal variedad procederá, a buen seguro, del porcentaje más elevado en el corpus de hombres como agentes y receptores de la injuria. Resulta evidente, por tanto, la necesidad de otros estudios pragmalingüísticos similares con los que cotejar este análisis. La comparación permitirá obtener, entonces sí, datos concluyentes sobre el comportamiento verbal femenino, en contraposición con el propio de los hombres.

Ha de apuntarse, no obstante, como apreciación final en este sentido el significado del tipo de respuesta mayoritaria, en hombres y mujeres, en relación con el acto de injuriar. La agresión verbal, que ocasiona, como ya se ha demostrado reiteradamente, un grave perjuicio social, provoca en el receptor una reacción que no pasa, en primera instancia, por negar o desmentir sino por devolver al emisor el mismo daño recibido, sin reparar en la verdad o falsedad de la injuria, antes bien, escogiendo entre la nómina de insultos socialmente establecidos como tales. 


\section{FINAL}

En definitiva, los textos de los siglos medios y áureos, jurídicos, doctrinales y literarios, plasmaron un ideal lingüístico que implicaba una clara estratificación social entre los que proferían palabras cazurras y villanas y los que hablaban apuesto, a la que acompañaba a su vez la distinción entre un discurso masculino frente a otro femenino. Este último fue alimentando tópicos, que definían a un tiempo el ideal femenino, propio de la mujer cortesana, y su contrario, caracterizador de la condición «vil y baja»-como suele denominarse en Autoridades-. El estereotipo ideal dibujaría a una mujer de prosodia refinada, que se expresaba en un tono dulce y suave, que rechazaría las palabras injuriosas, sutil en su conversación y hábil en el arte del eufemismo. Esta mujer prototípica debía cuidarse, sin embargo, en lo que a la lengua se refiere, del pecado de violencia verbal e infamia, que parecía encontrarse en su naturaleza. Además, existiría, como advierte la pícara Justina, una especial predilección de las mujeres por el enfrentamiento verbal contra otras mujeres, diferente al mismo tiempo del propiamente masculino.

Por su parte, la concreción de la realidad social de los siglos XVI y XVII, al menos la retratada en los pleitos navarros por injurias, nos devuelve mujeres que utilizan la violencia verbal, con independencia muchas veces de su condición social. Son mujeres que quebrantan el ideal lingüístico femenino en la medida en que hablan a altas voces, profiriendo palabras torpes y groseras, alejadas de toda sutileza, dulzura y eufemismo, y a las que en algunos casos se describe alejadas del comportamiento virtuoso. Agreden principalmente a otras mujeres, que reaccionan a su vez haciendo uso de la violencia verbal en un intercambio de insultos, que se presenta como la opción mayoritaria en la respuesta, seguida por la negación de la ofensa.

Estas mujeres, alejadas de los usos cortesanos, dejan claro que la violencia verbal y las injurias graves no eran solo propias de «capitanazos», lo que coincide con los resultados de estudios sobre otras geografías y cronologías, en las que figuran, asimismo, como emisoras y receptoras de insultos ${ }^{89}$.

Para otro momento queda completar este trabajo, cuyos resultados han de ser, por ahora, forzosamente provisionales, con idénticos análisis de otras zonas y con otros tipos de violencia verbal, tales como libelos y pasquines ${ }^{90}$, en los que también intervinieron las mujeres. 


\section{BiBLIOGRAFÍA}

Archer, Robert, Misoginia y defensa de las mujeres. Antología de textos medievales, Madrid, Cátedra, 2001.

Candau, María Luisa, «Disciplinamiento católico e identidad de género. Mujeres, sensualidades y penitencia en la España Moderna», Manuscrists, 25, 2007, pp. 211-237.

Candau, María Luisa, «Religiosidad, ocio y entretenimientos. Ocupando el tiempo de la mujer honesta (Fr. Alonso Remón, siglo XVII)», Cuadernos de Historia Moderna, 40, 2015, pp. 31-61.

Candau, María Luisa, «Emociones y lágrimas. Llantos y lamentos de mujeres», en Las mujeres y las emociones en Europa y América. Siglos XVIII-XIX, ed. María Luisa Candau, Santander, Universidad de Cantabria, 2016, pp. 59-91.

Cano, Rafael, «Apuesto y derecho, cortés y paladino: el ideal de la lengua en los textos alfonsíes», en Vues et contrevues. Actes du XIle Colloque International de Linguistique ibéro-romane. Université de Haute-Bretagne-Rennes 2, 2426 septiembre 2008, ed. Gabrielle Le Tallec-Lloret, Limoges, Lambert-Lucas, 2010, pp. 41-54. Disponible en <http://bit.ly/2h4ikdy [consulta: 14-04-2018]>.

Castillo, Antonio, «Voces, imágenes y texto. La difusión pública del insulto en la sociedad áurea», en Los poderes de la palabra. El improperio y la cultura hispánica en el Siglo de Oro, ed. Carmela Pérez-Salazar, Cristina Tabernero y Jesús M. Usunáriz, New York, Peter Lang, 2013, pp. 59-73.

Chauchadis, Claude, «Virtudes y pecados de la lengua: Sebastián de Covarrubias y Martín de Azpilcueta», Criticón, 92, 2004, pp. 39-45.

Coates, Jennifer, Mujer, hombres y lenguaje. Un acercamiento sociolingüístico a las diferencias de género, México, Fondo de Cultura Económica, 2009. [Original: Women, Men and Language. A Sociolinguistic Account of Gender Differences in Language, London/New York, Longman, 1986, 1993, 2004].

CORDE: Real Academia Española, Corpus diacrónico del español, <http://corpus. rae.es/cordenet.html> [consulta: 12-04-2018].

DA: Real Academia Española, Diccionario de Autoridades [1726-1739], Madrid, Gredos, 1979, 3 vols. <http://web.frl.es/DA.html> [consulta: 16-04-2018].

DCECH: Corominas, Joan, con la colaboración de José A. Pascual, Diccionario crítico etimológico castellano e hispánico, Madrid, Gredos, 2012 [1980-1991], ed. en cd-rom.

Fernández Poncela, Anna, Estereotipos y roles de género en el refranero popular, Barcelona, Anthropos, 2002.

Fuero Juzgo: Fuero Juzgo en latín y castellano cotejado con los más antiguos y preciosos códices, Madrid, Ibarra, 1815, disponible en <https://bit.ly/2qJ2mqe> [consulta: 12-04-2018]. 
Gil Ambrona, Antonio, Historia de la violencia contra las mujeres. Misoginia y conflicto matrimonial en España, Madrid, Cátedra, 2008.

González Ollé, Fernando, «Orígenes de un tópico lingüístico: alabanza de la lengua cortesana y menosprecio de la lengua aldeana», Boletín de la Real Academia Española, 79, 1999, pp. 197-219.

González Ollé, Fernando, «El habla cortesana: modelo principal de la lengua española», Boletín de la Real Academia Española, 82, 2002, pp. 153-231.

Jurado, Iván, «La "mala lengua" de la mujer: blasfemias, irreverencias y proposiciones», en Las mujeres y el honor en la Europa Moderna, ed. María Luisa Candau, Huelva, Universidad de Huelva, 2014, pp. 189-216.

Jurado, Iván, «Las injurias cotidianas: identidades e individuos en el siglo XV|», Bulletin of Spanish Studies, 92.5, 2015, pp. 677-697.

Lakoff, Robin, Language and Woman's Place: Text and Commentaries, Oxford, Oxford University Press, 2004.

López-Cordón, María Victoria, «La conceptualización de las mujeres en el Antiguo Régimen: los arquetipos sexistas», Manuscrits, 12, 1994, pp. 79-107.

Maiza, Carlos, «Injuria, honor y comunidad en la sociedad navarra del siglo XVIII», Príncipe de Viana, 53, 1992, pp. 685-696.

Martínez Garrido, Elisa, «Palos, animales y mujeres. Expresiones misóginas, paremias y textos persuasivos», Cuadernos de Filología Italiana, 8, 2001, pp. 79-98.

Mendoza, Juan Miguel, Delincuencia y represión en la Castilla bajomedieval (los territorios castellano-manchegos), Granada, Grupo Editorial Universitario, 1999.

Martínez Góngora, Mar, Discurso sobre la mujer en el humanismo renacentista español. Los casos de Antonio de Guevara, Alfonso y Juan de Valdés y Luis de León, York (South Carolina), Spanish Literature Publications Company, 1999.

Morant, Isabel, «Hombres y mujeres en el discurso de los moralistas Funciones y relaciones", en Historia de las mujeres en España y América Latina II. El mundo moderno, dir. Isabel Morant, Madrid, Cátedra, 2005, pp. 27-62.

Ortega, Margarita, «Cuerpo e identidad de las mujeres en el Antiguo Régimen», en De la Edad Media a la Edad Moderna. Mujeres, educación y familia en el ámbito rural y urbano, coord. María Teresa López Beltrán, Málaga, Servicio de Publicaciones e Intercambios, 1999, pp. 185-206. 
Partidas: Las siete partidas del rey don Alfonso el Sabio, cotejadas con varios códices antiguos por la Real Academia de la Historia, tomo 2: Partida Segunda y Tercera, Alicante, Biblioteca Virtual Miguel de Cervantes, $2008<\mathrm{https}$ ///bit. ly/2vn9Epj> [consulta: 18-04-2018] y Las siete partidas del rey don Alfonso el Sabio, cotejadas con varios códices antiguos por la Real Academia de la Historia, tomo 3: Partida Quarta, Quinta, Sexta y Septima, Alicante, Biblioteca Virtual Miguel de Cervantes, 2008 <https://bit.ly/2qlqOrQ> [consulta: 18-042018].

Pérez Molina, Isabel, «La normativización del cuerpo femenino en la Edad Moderna: vestido y virginidad», Espacio, Tiempo y Forma, Serie IV, Historia Moderna, 17, 2004, pp. 103-116.

Pérez Molina, Isabel et al. (coords.), Las mujeres en el Antiguo Régimen: imagen y realidad (siglos XVI-XVIII), Barcelona, Icaria, 1994.

Pícara: López de Úbeda, Francisco, Libro de entretenimiento de la pícara Justina, ed. David Mañero Lozano, Madrid, Cátedra, 2012.

Ruiz Astiz, Javier, «Libelos y pasquines en la Navarra moderna: análisis y estudio del protagonismo de las mujeres», en Feminismo e interculturalidad: V Congreso internacional AUDEM, ed. Ángeles Cruzado y Amalia Ortiz de Zárate, Sevilla, ArCibel Editores, 2008, pp. 381-400.

Ruiz Astiz, Javier, «La participación de la mujer en los desórdenes públicos: análisis de su presencia en la Navarra moderna», Sancho el Sabio. Revista de cultura e investigación vasca, 33, 2010, pp. 11-34.

Ruiz Astiz, Javier, «Cencerradas y matracas en Navarra durante el Antiguo Régimen: funciones y objetivos», Hispania. Revista española de Historia, 73, 2013, pp. 733-760.

Ruiz Ortiz, María, «Normas y resistencias femeninas: una mirada cotidiana a través de las Sumas de confesión (ss. XVI-XVIII)», en Las mujeres y el honor en la Europa Moderna, ed. María Luisa Candau, Huelva, Universidad de Huelva, 2014a, pp. 165-188.

Ruiz Ortiz, María, «Pecados femeninos y vida privada: discursos sobre la conciencia y la vida cotidiana en la España Moderna (ss. XVI-XVII)», Cuadernos de Historia Moderna, 2014b, 39, pp. 59-76.

Segura Urra, Félix, «Verba vituperosa: el papel de la injuria en la sociedad bajomedieval», en Aportaciones a la historia social del lenguaje: España, siglos XIVXVIII, ed. Rocío García-Bourrelier y Jesús M. Usunáriz, Madrid/Frankfurt am Main, Iberoamericana/Vervuert, 2006, pp. 149-195.

Serra, Rafael, Honor, honra e injuria en el derecho medieval español, Murcia, Universidad de Murcia, 1969.

Tabernero, Cristina, «Injurias, maldiciones y juramentos en la lengua española del siglo XVII», Revista de Lexicografía, 16, 2010, pp. 101-122. 
Tabernero, Cristina, «Léxico injurioso y tipos de discurso en el Siglo de Oro», en Los poderes de la palabra. El improperio y la cultura hispánica en el Siglo de Oro, ed. Carmela Pérez-Salazar, Cristina Tabernero y Jesús M. Usunáriz, New York, Peter Lang, 2013, pp. 257-275.

Tabernero, Cristina, «Indicadores sociolingüísticos y pragmáticos del insulto (siglos XVI y XVII)», en Actas del X Congreso Internacional de Historia de la Lengua Española, ed. M. Luisa Arnal, Rosa M. Castañer, J. M. ${ }^{a}$ Enguita, V. Lagüéns y M. Antonia Martín Zorraquino (eds.), Zaragoza, Institución «Fernando el Católico», 2018a, vol. 2, pp. 1459-1477.

Tabernero, Cristina, «Veceras de mal decir e infamadas: el insulto femenino en la interacción comunicativa del Siglo de Oro», Hipogrifo. Revista de literatura y cultura del Siglo de Oro, 6.2, 2018b, pp. 729-756.

Undurraga, Verónica, Los rostros del honor. Normas culturales y estrategias de promoción social en Chile colonial, siglo XVIII, Santiago de Chile, Ediciones de la Dirección de Bibliotecas, Archivos y Museos, 2012.

Usunáriz, Jesús M., «El lenguaje de la cencerrada: burla, violencia y control en la comunidad», en Aportaciones a la historia social del lenguaje: España, siglos XIV-XVIII, ed. Rocío García-Bourrelier y Jesús M. Usunáriz, Madrid/Frankfurt am Main, Iberoamericana/Vervuert, 2005a, pp. 197-217.

Usunáriz, Jesús M., «Verbum maledictionis. La blasfemia y el blasfemo de los siglos XVI y XVII», en Aportaciones a la historia social del lenguaje: España, siglos XIV-XVIII, ed. Rocío García-Bourrelier y Jesús M. Usunáriz, Madrid/Frankfurt am Main, Iberoamericana/Vervuert, 2005b, pp. 235-260.

Usunáriz, Jesús M., «Un análisis de los insultos en el Quijote desde la historia social del lenguaje», Anales cervantinos, 49, 2017, pp. 59-73.

Zapatero, Alberto, «La mujer española y el discurso moralista en Nueva España (siglos XVI-XVII)», en Familia y organización social en Europa y América, siglos $X V$-XX, ed. Francisco Chacón, Juan Hernández y Francisco García González, Murcia/Albacete, Universidad de Murcia, 2007, pp. 14-42. 